\title{
OBSERVATIONS ON A PATIENT WITH THE MALIGNANT CARCINOID SYNDROME
}

\author{
BY \\ J. A. KIRKLAND, ROSEMARY CASS, K. G. LOWE, AND S. F. SOUTAR \\ From the Departments of Pathology, Pharmacology, Medicine, and Surgery, the University of St. Andrews \\ and the Royal Infirmary, Dundee
}

(RECEiVED FOR PUBLICATION APRIL 27, 1959)

The syndrome of malignant carcinoid tumour with excessive production of 5-hydroxytryptamine (5-HT, serotonin, enteramine) is currently of great interest (Mattingly, 1956 ; MacDonald, 1956 ; Ritchie, 1956; Thorson, 1958). As well as reporting clinical, pharmacological, and necropsy data from a typical case, this paper describes for the first time changes in the pulmonary vasculature that may be relevant to the pulmonary hypertension occurring in some cases with carcinoid tumour.

Special attention has also been given to the fixation and staining of carcinoid tumours, and a new staining method is described which suggesis that there is only one type of cell in these tumours.

\section{Case Report}

Mrs. C. W., aged 62, was admitted to the Royal Infirmary, Dundee, on November 19, 1956. For about one year she had had vague right upper abdominal pain, and for some six months had been losing weight (2 stone) and had had diarrhoea (average, three to four loose stools daily). She had had bleeding haemorrhoids for many years but no other illness of note.

On examination, she was rather obese and florid with marked venous telangiectasis of the face, but she stated that she came from rather florid stock and her appearance had hitherto not caused comment. Blood pressure was $175 / 95 \mathrm{~mm}$. $\mathrm{Hg}$. There was a mass in the right hypochondrium with tenderness and guarding over it. At laparotomy (November 22) a Meckel's diverticulum, containing a hard nodule, was removed and biopsy was taken of one of many metastatic deposits in the liver.

Histological Report (No. 2098/56). - Dr. W. W. Park reported that there were two specimens: (a) a Meckel's diverticulum, $3 \mathrm{~cm}$. long and $2 \mathrm{~cm}$. wide, containing in the wall at its distal end a firm oval nodule $6 \mathrm{~mm}$. in diameter and of a grey-white colour on gross section, and $(b)$ a narrow wedge of firm greywhite (liver) tisste. Sections showed the following features.
Nodule in Diverticulum.-This is an argentaffin carcinoma (carcinoid tumour) spreading widely into the muscular coats of the diverticulum and through them into the subserosa. The growth shows an unusually glandular structure.

Liver Biopsy. - This shows almost complete replacement of liver parenchyma by argentaffin carcinoma, with the same unusually glandiform structure.

The patient made a good recovery and went home on December 11, but her right upper abdominal discomfort continued and she returned to hospital on March 11, 1957. It was found that these symptoms could be largely relieved by codeine and she was discharged home.

Cardiac Catheterization.-The patient and her relatives were most co-operative, and after the procedure had been fully discussed with them the patient volunteered for this procedure, which was carried out uneventfully on March 21.

Haemodynamic studies showed no abnormality. Pressure pulse patterns were normal. Pressures were $22 / 10,22 / 0$, and $0 \mathrm{~mm}$. $\mathrm{Hg}$ in the pulmonary artery, right ventricle, and right atrium respectively. There was, therefore, no pulmonary hypertension and no demonstrable stenosis or incompetence of pulmonary or tricuspid valves. No unusual pattern was seen at routine intracardiac electrocardiography.

Subsequent Progress. - The patient enjoyed reasonable health for some months, but the liver continued to enlarge and she needed increasing amounts of codeine for relief of pain. In August, 1957, the pain and diarrhoea increased, she became weak and anorexic, and she was admitted to hospital for the last time on September 5, 1957. She was still well nourished but extremely lethargic. The liver had grown much larger since her last admission. Blood pressure was $150 / 75 \mathrm{~mm}$. Hg. There was still no? evidence of disease in the cardiovascular and 7 respiratory systems. She had rather a sore red tongue and throat but no skin rash suggestive of pellagra, which has been reported as complicating this syndrome (Bridges, Gibson, Loughridge, and Montgomery, 1957). She went progressively downhill and died on September 9. 


\section{Chemical Studies}

These studies were made during the last nine months of the patient's life, and after her death on tissues obtained at necropsy.

Methods.-These were as follows :

(1) The 5-H was extracted from blood, plasma, and necropsy tissue with acetone, evacuated to dryness in vacuo, and taken up in saline solution for biological assay on the atropinized oestrous uterus of the rat. Extracts were retested in the presence of the specific 5-HT antagonist, lysergic acid diethylamide.

(2) For chromatography, spots of extracts from the organic phase together with reference markers of 5-HT creatinine sulphate and 5-hydroxyindoleacetic acid (5-HIAA) were placed on Whatman No. 4 filter paper, run ascending in butanol-acetic-acid-water $(4: 5: 1)$ overnight, dried, and developed with Ehrlich's reagent.

(3) The 5-HIAA in urine was estimated by the method of Macfarlane, Dalgliesh, Dutton, Lennox, Nyhus, and Smith (1956).

(4) The histamine contents of blood and urine were estimated for us by Dr. R. G. Mitchell, Department of Paediatrics, University of St. Andrews, using Code's (1937) modification of the Barsoum-Gaddum method for determining histamine in blood, and the method of Roberts and Adam (1950) for histamine in urine.

The blood samples were drawn from peripheral veins and separated within minutes. Those of January 21 , 1957, and January 28, 1957, were obtained in siliconed syringes, but the sample of September 7, 1957, was obtained in a dry syringe. The platelet layers and supernatant plasmas of the siliconed samples of January 21, 1957, and January 28, 1957, were extracted separately; the 5-HT content was wholly in the platelet layers, there being none in the plasma. The sample of September 7 was platelet-free, the platelets having presumably ruptured during sampling and released their 5-HT content into the plasma.

At cardiac catheterization, despite the use of a nylon catheter and siliconed syringes, all blood samples were devoid of platelets.

Urine was collected over 24 hours in a bottle containing $25 \mathrm{ml}$. glacial acetic acid and $3 \mathrm{ml}$. toluene.

Results. - The results of the estimations of 5-HT in blood and 5-HIAA in urine are shown in Tables I and II. The 5-HT content of various tissues was assayed post mortem, and the results are shown in Table III. The hepatic and cardiac nodules were surrounded by normal tissue and the ratio of normal tissue to metastatic carcinoid, in the pieces of tissue analysed, was not known.

The histamine level in the blood on January 21 was $0.06 \mu \mathrm{g} . / \mathrm{ml}$., the basophil count being $63 / \mathrm{c} . \mathrm{mm}$. and the eosinophil count $238 / \mathrm{c} . \mathrm{mm}$. During the preceding 24 hours urine had been collected for histamine determination, and its
TABLE I

RESULTS OF ESTIMATIONS OF 5-HT IN BLOOD AND 5-HIAA IN URINE

\begin{tabular}{|c|c|c|}
\hline Date & $\begin{array}{c}\text { Blood Content } \\
\text { of 5-HT } \\
(\mu \mathrm{g} . \text { per ml. })\end{array}$ & $\begin{array}{l}\text { Urinary Content of } \\
\text { 5-HIAA (mg. per } \\
\text { 24-hour Output) }\end{array}$ \\
\hline $\begin{array}{r}25 / 11 / 56 \\
30 / 11 / 56 \\
21 / 1 / 57 \\
28 / 1 / 57 \\
7 / 9 / 57\end{array}$ & $\begin{array}{l}\overline{-} \\
0.133 \text { (whole blood) } \\
0.24 \text { ( }, \overline{\text {, }} \\
0.25 \text { (platelet-free } \\
\text { plasma) }\end{array}$ & $\begin{array}{r}160 \\
204 \\
96 \\
300\end{array}$ \\
\hline
\end{tabular}

TABLE II

PLASMA CONTENT OF 5-HT AFTER CARDIAC CATHETERIZATION

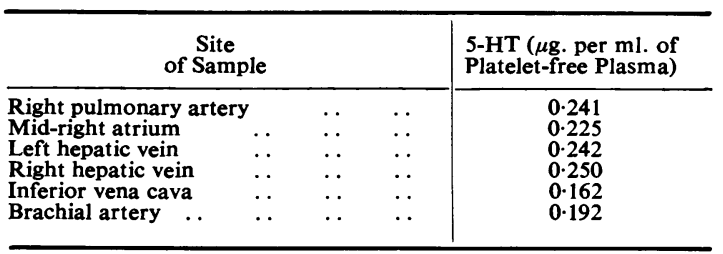

TABLE III

ASSAY OF 5-HT CONTENT OF POST-MORTEM TISSUE

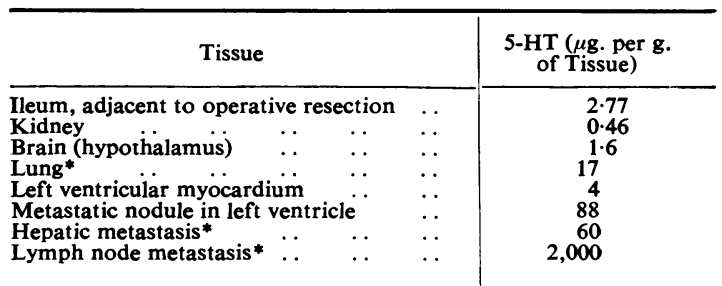

* 5-HT content was confirmed by paper chromatography; on each paper a trace of 5-HIAA seen, but no evidence of 5-hydroxytryptophan (5-HTP) in any.

TABLE IV

COMPARISON OF VALUES FOR 5-HT AND 5-HIAA IN PERNOW AND WALDENSTROM:S (1957) AND PRESENT CASES

\begin{tabular}{l|c|c|c}
\hline & Normal & $\begin{array}{c}\text { Carcinoid } \\
\text { Syndrome }\end{array}$ & $\begin{array}{c}\text { Present } \\
\text { Case }\end{array}$ \\
\hline Serum 5-HT ( $\mu \mathrm{g} . / \mathrm{ml}.) \ldots$ & 0.03 & 0.2 & 0.133 \\
Urine 5-HIAA (mg./24 & 2 to 0.2 & to 0.6 & 60 to \\
$\begin{array}{l}\text { to } 0.25 \\
\text { hours) }\end{array}$ & 2,000 & 300 \\
\hline
\end{tabular}

content of free histamine was found to be 8.3 $\mu \mathrm{g}$. $/ 24$ hours. Dr. Mitchell regards the values for blood and urine as well within the range of normal for healthy adults (Mitchell and Code, 1954; Mitchell, Butt, and Code, 1954).

Comparison of our figures for 5-HT and 5-HIAA with those of Pernow and Waldenström (1957) shows that our case is typical of the functioning malignant carcinoid syndrome (Table IV). 
Moreover, at necropsy the 5-HT content in a lymph node metastasis was $2 \mathrm{mg}$. per g. of tissue, comparable to the findings in other cases (Lembeck, 1953 ; Sjoerdsma, Weissbach, Terry, and Udenfriend, 1957).

Blood 5-HT Content from Different Vascular Sites.-Goble, Hay, and Sandler (1955), studying a case of carcinoid syndrome, found that the free plasma 5-HT (as distinct from platelet-bound 5-HT) was reduced in amount during its passage through the lungs; they attribute this to the removal of 5-HT by the enzyme mono-amine oxidase in the lungs in high concentration. In cardiac catheterization of six patients with the carcinoid syndrome, Sjoerdsma and his colleagues (1956, 1957) failed to confirm this finding. They stress the difficulty of separating plasma from formed elements and state that proof of pulmonary arteriovenous 5-HT difference must await the elaboration of more reliable methods. Our patient had been found earlier in the course of her illness to have no free plasma 5-HT (Table I). At cardiac catheterization, two months later, blood was withdrawn from several vascular sites (Table II). These samples were poor in platelets or else there were none; thus the plasma content of 5-HT could be attributed largely or entirely to rupture of platelets during sampling. There was no gross difference between the 5-HT content of the hepatic venous, pulmonary arterial, and brachial arterial blood samples. In view of the complicating views mentioned above and the technical difficulties involved, it is obviously desirable to pursue such catheterization studies if clinically justifiable once technical methods have been improved. In the present case, there were numerous metastatic deposits both in the lungs and in the left ventricular wall ; these could well have been contributing 5-HT directly into the greater circulation and thereby eliminated any evidence of destruction of 5-HT in the pulmonary traverse.

Histamine Excretion-Some cases of the carcinoid syndrome have increased blood levels and urinary excretion of histamine, the excess of 5-HT perhaps producing secondary release of histamine (Pernow and Waldenström, 1957). Our patient, however, had normal levels of blood and urinary histamine.

\section{Necropsy (N/2877/57)}

There was no abnormality of the head and neck. A small effusion was present in each pleural cavity. The lungs (right 270 g., left 225 g.) appeared normal.
In the heart $(350 \mathrm{~g}$.) there were three nodules of pale tumour tissue within the myocardium of the left ventricle. There was no ventricular hypertrophy and the heart valves were healthy apart from slight fibrous thickening at the base of the pulmonary valve, which was not stenosed and was completely competent.

There were a few peritoneal adhesions over the upper surface of the enlarged liver $(2,950 \mathrm{~g}$.), but no peritoneal effusion. The liver substance was almost totally replaced by yellowish-brown tumour tissue as were all the lymph nodes in the porta hepatis. Thirty centimetres proximal to the ileocaecal valve there were numerous adhesions at the site of the surgical resection. The bowel lumen, however, was fully patent and there was no evidence of tumour here or in any other portion of the gastro-intestinal tract, including the appendix.

Small nodules of metastatic tumour were found in the otherwise normal-looking spleen, pancreas, and kidneys. The uterus was enlarged to twice its normal size by several intramural and subserous fibroids, but was free from secondary deposits.

Histology of the Tissues.-The tissues were fixed by the standard method of $10 \%$ formol saline followed by formol corrosive, saturated corrosive, dehydration, and paraffin embedding (Lendrum, 1951).

All sections of the lungs show numerous secondary nodules, many consisting of only a few cells, distributed in random fashion with no constant relation to blood vessels or lymphatics. Metastases are also present in the left ventricle (Fig. 1), both kidneys, liver, lymph nodes, and spleen. Mitoses are rare.

The pulmonary valve appears to be within normal limits and Weigert's stain for elastica shows the usual elastica pattern without any of the changes noted by MacDonald and Robbins (1957) in carcinoid fibrostenosis.

Sections were stained by the diazonium dye fast red B (Pearse, 1953) and by Davenport's modification of Bodian's protargol procedure in an attempt to demonstrate the so-called " argentaffin " and " argyrophil" cells. Argentaffin cells are said by Jacobson (1957) to show red or reddish-brown granules with the diazonium method and black granules with both Masson Fontana and with Davenport's method, whereas " argyrophil" cells react only with Davenport's method. In our case, the Davenport method shows black or brown granules in nearly every cell which on the basis of other methods is not autolysed; the diazo-positive cells, on the other 


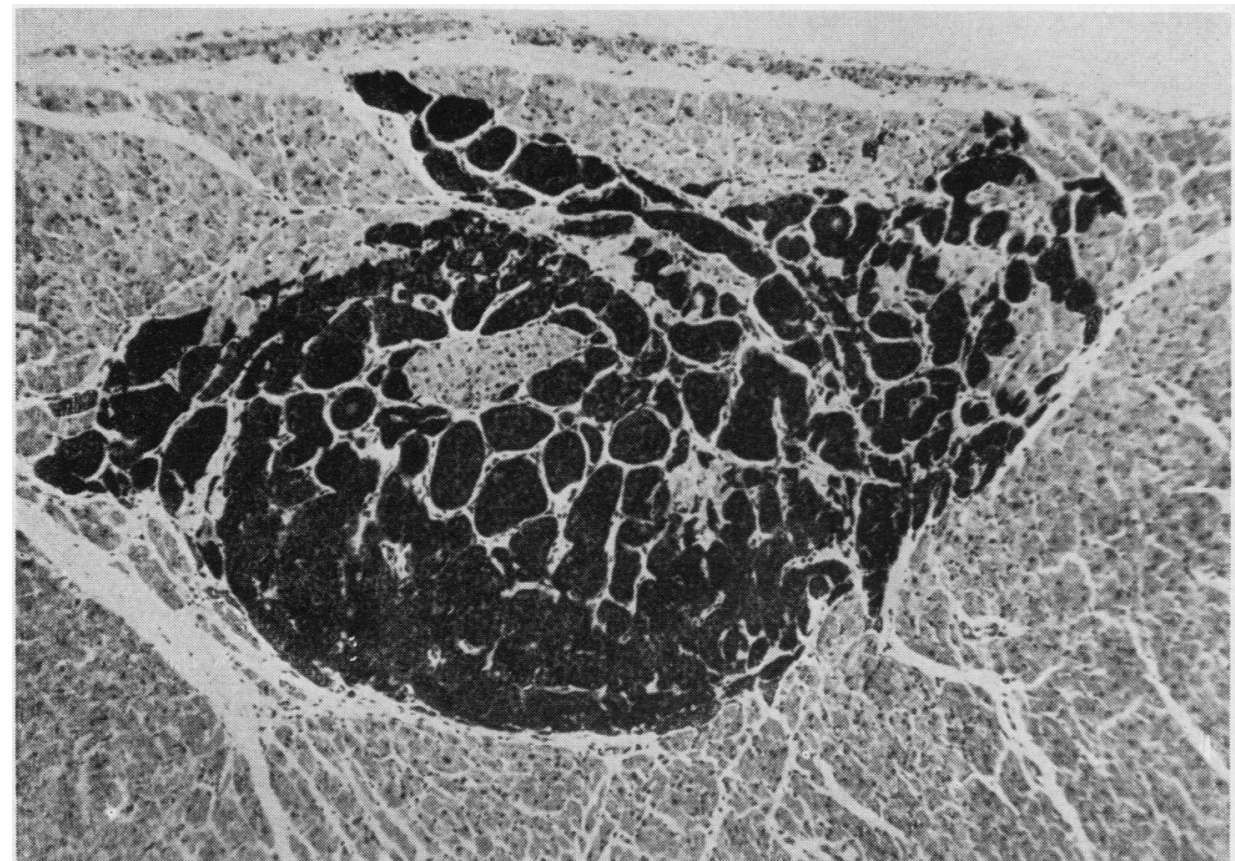

FIG. 1.-Left ventricle, $\times 75$. The phloxinophilia of the tumour cells in this metastasis shows up darkly, thanks to a minus-red filter. Note the occasional acinar formation. Stained: phloxin, "lissamine" flavine (Dundee 58-A). Present case.

hand, are scanty, being confined to the periphery of large masses of cells or to groups of only a few cells.

Sections from the various metastases were also stained by a method recently elaborated by Lendrum and Fraser (see Appendix). This modification of the phloxin-tartrazine method (Lendrum, 1939, 1947) has now been tested by these workers on over 50 examples of carcinoid, and the following paragraphs are a joint statement based on the conclusions they have already reached.

The method shows in well-fixed tissue an aggregation of strongly red (phloxinophilic) granules at the basal, subnuclear part of those tumour cells that lie at the periphery of tumour masses. Towards the centre of the larger masses and also gradually as one moves in from the surface of the block, the granules disappear, being replaced, as it were temporarily, by a structureless red staining of the cytoplasm. This gradation of preservation of the granules is related in part to inadequate penetration even with the best fixative (formol corrosive). The poorer the fixation, as measured by cytological definition and tinctorial specificity with other stains, the fewer cells are seen with sharply defined phloxinophilic granules. Fresh tissue in suitably small blocks if well fixed either by formalin, which happens sometimes, or by the more consistent formolcorrosive will show equally good phloxinophilic demonstration of the granules. Apart from fixation, the absence of granules and even of diffuse phloxinophilia in the centre of the larger masses of tumour cells is largely the result of degenerative change, as occurs in the masses of encephaloid carcinoma; comparable change is also seen in post-mortem material and the loss is most obvious in tissue from the bowel wall and hepatic metastases. These autolytic changes are accompanied by deterioration in the quality of the nuclear and other staining.

In the adenomatoid areas, which in the present case were particularly obvious in the hepatic and renal metastases, the lumen commonly contained a circular mass which was strongly P.A.S. positive and also showed an extreme retention of phloxin, even in those parts where the tumour cells were so autolysed that they had lost all phloxinophilia.

The Pulmonary Vasculature.-Fifteen blocks of lung were fixed, three from each of the five major lobes. Sections were stained by Weigert's elastica method and the arterioles (vessels less than $100 \mu$ in diameter) were measured with the aid of an 
ocular micrometer. The same various diameters were measured on sections, similarly prepared, from five normal controls, one case of severe mitral stenosis, and a case of primary pulmonary hypertension.

The Measurements. - Various authorsValenzuela, Toriello, and Thomas (1954), Goodale and Thomas (1954), Denst, Edwards, Neubuerger, and Blount (1954), O'Neal, Thon as, and Hartroft (1955), and Heath and Whitaker (1956)-have given their histological criteria for a diagnosis of pulmonary hypertension, but they are by no means agreed on a common method. Valenzuela et al., Goodale et al., and Heath et al., however, are agreed that pulmonary vessels whose external diameter is less than $100 \mu$ should only have one layer of elastica, no media, and a wall thickness less than $15 \%$ of the external diameter.

For the purpose of this investigation measurements were made of the external diameter, wall thickness, and lumen diameter in all cases and finally expressed as a percentage ratio between the wall thickness and the external diameter. Only vessels cut in cross-section or near crosssection were measured, all measurements being made in the same diameter. When the vessel wall varied in thickness, at least two separate measurements were made in different diameters of what was considered to be a representative section of the wall. Measurement of the vessel lumen was used merely to confirm the accuracy or otherwise of the wall thickness and external diameter.

Such an estimation at least allows a comparison to be made between the pulmonary vessels of the control cases and those of the present case of malignant carcinoid, although our findings in this latter might, to some authors, be not indicative of pulmonary hypertension.

Results.-In the normal control lungs 100 vessels were measured; 34 vessels had a wall thickness external diameter less than $10 \%, 52$ vessels were between 10 and $15 \%$, nine vessels were between 16 and $20 \%$, and five vessels between 21 and $25 \%$. In the case of severe mitral stenosis a shift to the right was noted ; one vessel less than $10 \%$, nine between 10 and $15 \%, 18$ between 16 and $20 \%$, three between 21 and $25 \%$, and five between 26 and $30 \%$. A similar picture was seen in the case of primary pulmonary hypertension; of 84 suitable vessels, seven were less than $10 \%, 46$ between 10 and $15 \%, 19$ between 16 and $20 \%$, eight between 21 and $25 \%$. two between 26 and $30 \%$, and two greater than $30 \%$ (Figs. 2, 3, and 4).
In the case of malignant carcinoid, not only was there a shift to the right, but there was also a wider scatter of results with considerable flattening of the scale. Eighty-five vessels were suitable for measurement ; 19 were less than $10 \%$, 24 between 10 and $15 \%, 24$ between 16 and $20 \%$, 10 between 21 and $25 \%$, and eight between 25 and $50 \%$ (Fig. 5).

Study of the lobar distribution of the vascular changes showed that the changes were more severe in the right lung (Table V), and, although

TABLE V

DISTRIBUTION OF VASCULAR CHANGES AS RATIO OF WALL THICKNESS TO DIAMETER

\begin{tabular}{l|c|c|c|c|c|c}
\hline $\begin{array}{c}\text { N 2877 } \\
\text { Carcinoid }\end{array}$ & $\begin{array}{c}\text { No. of } \\
\text { Vessels }\end{array}$ & $10 \%$ & $10-15 \%$ & $16-20 \%$ & $21-25 \%$ & $26-50 \%$ \\
\hline $\begin{array}{l}\text { Right lung } \\
\text { Left , }\end{array}$ & 53 & $\begin{array}{r}72 \\
\hline\end{array}$ & $\begin{array}{c}16 \\
8\end{array}$ & $\begin{array}{c}14 \\
10\end{array}$ & $\begin{array}{l}9 \\
1\end{array}$ & \begin{tabular}{l}
7 \\
\hline
\end{tabular} \\
\hline
\end{tabular}

the number of vessels suitable for measurement in the sections from any given lobe was rather small, it was none the less possible to state with fair assurance that the change was more prominent in the right upper lobe than in the right lower lobe.

We make these observations on the zonal differences without comment, except to say that these arteriolar changes may have no relation to the narrowing described by Harrison (1958); in his studies on post-mortem angiography he noted no difference between the lungs, nor between the lobes in primary pulmonary hypertension, whereas the narrowing was distinctly more intense in the lower lobes in mitral stenosis.

The recognition microscopically of pulmonary hypertension is undoubtedly possible, but we believe that the degree of pulmonary hypertension can only be assessed accurately after the laborious method of measuring suitable vessels and comparison with control material prepared in a similar manner.

Since the lungs in all eight cases were prepared in a fairly comparable way it seems reasonable to believe that any fallacies due to artefact would cancel out. Further, the similarity of the control cases as a group and their statistically significant difference from the two hypertensive cases suggest that the measurements provide objective information. Finally, the facts observed in the carcinoid material would seem to indicate that the mechanism of pulmonary hypertension had been set afoot there.

\section{Discussion}

In 1888 Lubarsch described a primary tumour of small bowel and appendix which he called a 


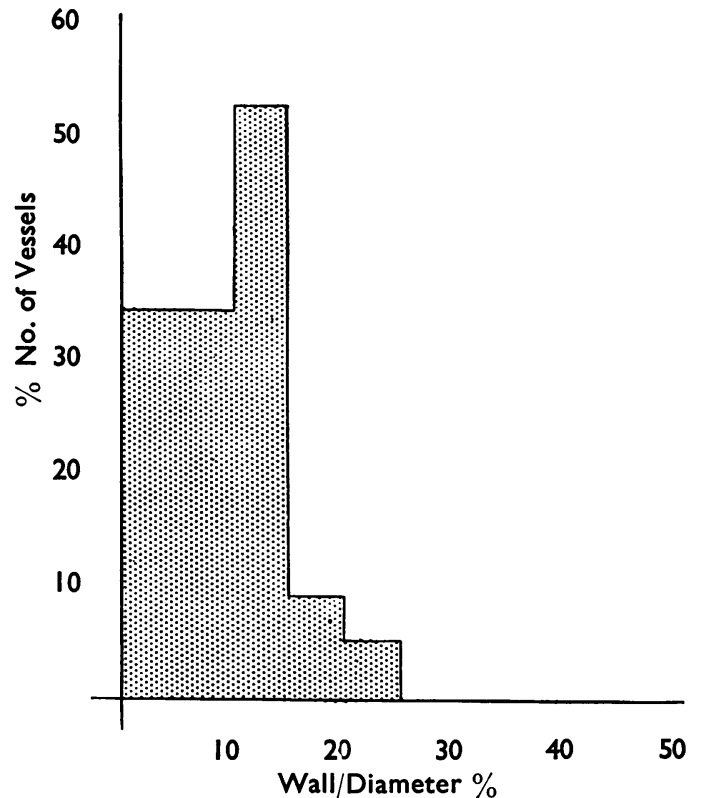

FIG. 2.-Diagram of measurements of 100 vessels, $40-100 \mu$ diameter, end-nn, from five control cases as follows:

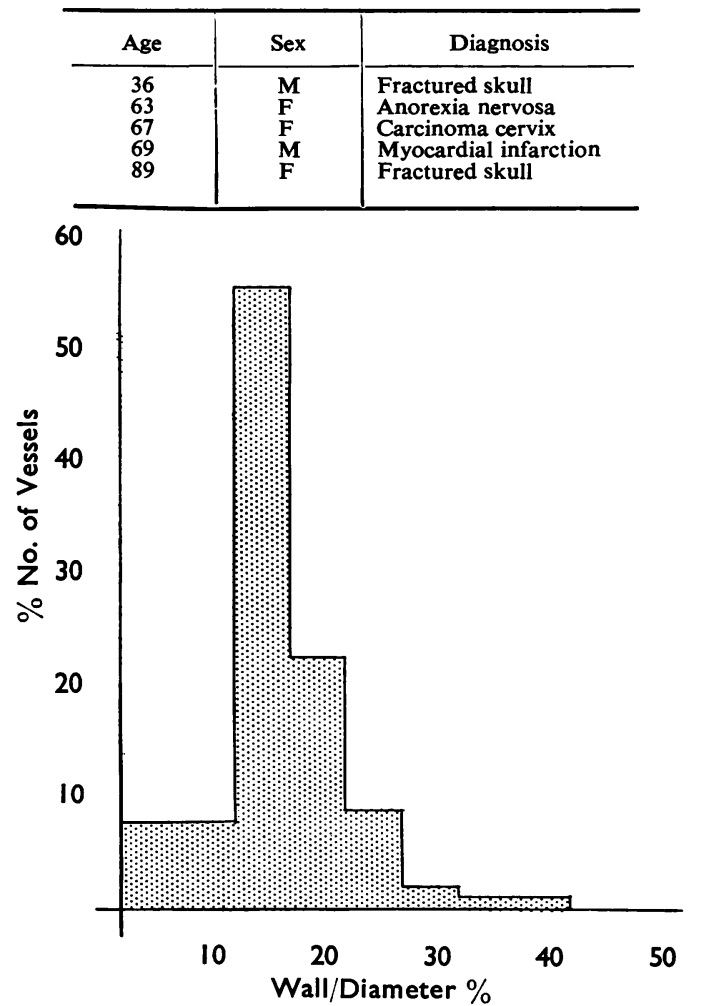

Fig. 4.-Diagram of measurements of 84 vessels, $40-100 \mu$ diameter, end-on, in a case of primary pulmonary hypertension in a man aged 34 .

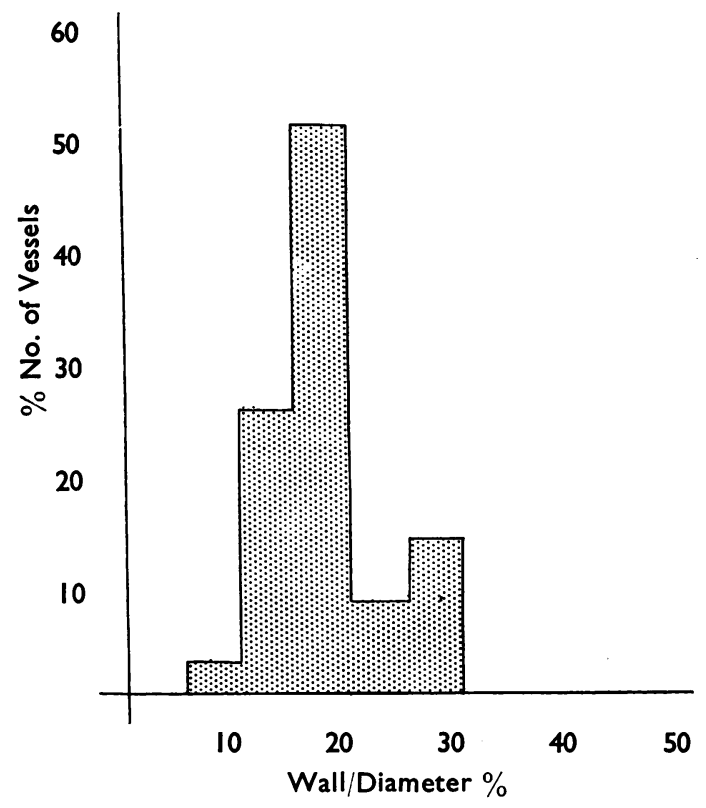

Fig. 3.-Diagram of measurements of 36 vessels, 40-100 $\mu$ diameter, end-on, in a case of severe mitral stenosis in a man aged 57.

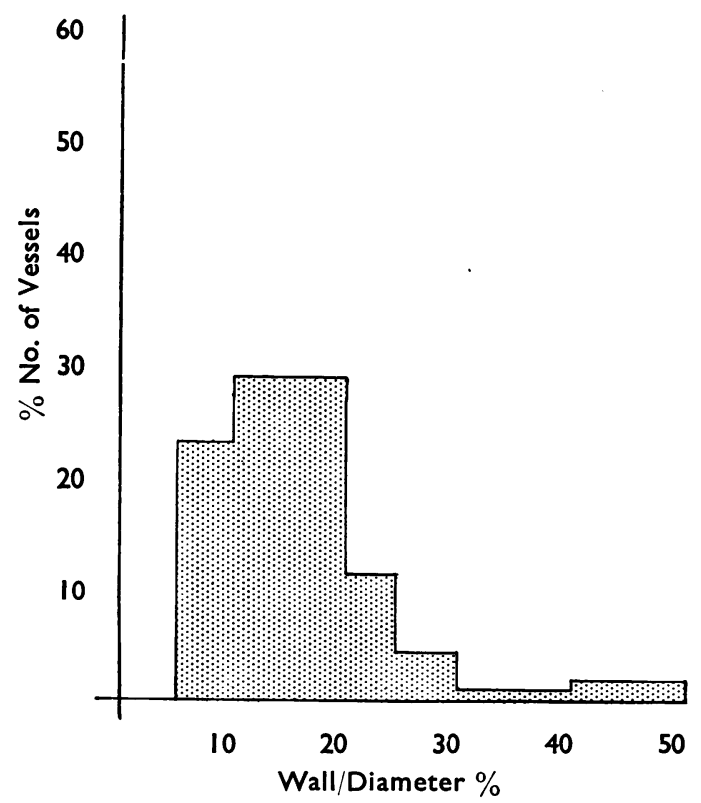

FIG. 5.-Diagram of measurements of 85 vessels, $40-100 \mu$ diameter, end-on, from 15 different sections in a case of malignant carcinoid in a woman aged 62 . 
"little carcinoma," later termed " carcinoid" by Oberndorfer (1907). Pierre Masson showed in 1914 that the tumour contained intracytoplasmic granules which reduced silver salts, and he proposed the name "argentaffin tumour." $\mathrm{He}$ also postulated an endocrine function which at last he has had the satisfaction of seeing confirmed.

Site of Primary Tumour.-The primary tumour was situated in a Meckel's diverticulum, one of the rarer sites. MacDonald found nine such cases in the literature and added two cases from his own series of 140 extra-appendiceal carcinoid tumours. Another case has since been described by Smith and Campbell (1956), which with the present case brings the total to 13 .

Haemodynamic Data. - In this patient, as in two of the three cases studied by Sjoerdsma et al. (1956), there were no abnormal findings at catheterization of the right heart. In the cases of Biörck, Axén, and Thorson (1952) and Goble, Hay, Hudson, and Sandler (1956) there were abnormal right heart pressure recordings due to valvular disease.

Early in the study of the malignant carcinoid syndrome it had been guessed that a cause of right heart disease might be pulmonary arteriolar constriction by 5-HT, thereby raising the pulmonary vascular resistance (Thorson, Biörck, Björkman, and Waldenström, 1954 ; Jenkins and Butcher, 1955). This suggestion was refuted by Goble et al. (1956), who showed normal pulmonary vascular resistance even during flushing, when circulating $5 \mathrm{HT}$ was in fact increased to a very high level. The following year, Sjoerdsma et al. (1957) reported an example of raised pulmonary artery pressure $(40 / 20 \mathrm{~mm}$. $\mathrm{Hg})$; their patient had suffered frequent asthmatic attacks, attributable to 5-HT, but there is no real evidence that the raised pulmonary arterial pressure was not merely due to his chronic pulmonary damage.

Clinically our patient showed the most constant feature of the syndrome, namely, chronic diarrhoea. She had a pronounced flush, but its diagnostic value was uncertain since she stated that other members of her family were also florid. She had no clinical evidence of the less common features such as acquired cardiac disease, bronchospasm, or arthropathy (Sjoerdsma et al., 1956).

Histochemistry.-Special attention was paid to the staining properties of the tumour cells because of the suggestion by Hamperl (1952) and Jacobson (1957) that there are two types of tumour cell, argentaffin and argyrophil (Hamperl and Lattes,
1957). Since then, Sandler and Snow (1958) have suggested that argentaffin cells secrete 5-hydroxytryptamine (5-HT) and argyrophil cells secrete 5-hydroxytryptophan (5-HTP). They described three unusual cases of atypical malignant carcinoid syndrome (one of their own, and two quoted from the literature) in which there was patchy flushing attenuated by antihistamine drugs. The tumour cells lacked argentaffin granules and examination of the urine showed excretion of 5-HTP and greatly increased excretion of 5-HT and histamine. They guess that tumour tissue may in future be found to contain both argentaffin and argyrophil cells in varying concentrations and that both 5-HT and 5-HTP may be secreted by the tumours. In our case no 5-HTP was found at necropsy although the tumour contained a predominance of argyrophil cells, the argentaffin cells being extremely scanty.

The granules of enterochromaffin cells (Kultschitzky, 1897) in the bowel and in the carcinoid tumours studied are easily and effectively demonstrated by the new method of Lendrum and Fraser if cytological preservation is good. The granules in many of the cells also give a positive although much less obvious reaction with the diazo method, with Schmorl's method as modified by Laskey and Greco (1948), and with Verhoeff's stain for elastica. In the present case, tissues were fixed within four hours of death and excellent phloxinophilia of the granules was found in the cardiac, pulmonary, renal, lymph node, and splenic metastases. The hepatic nodules were more autolysed and gave poorer results with the new method and almost negative results with the Davenport technique, but this latter finding has to be interpreted with caution because Lendrum and Fraser have found that although formolcorrosive is ideal as a fixative for the new method it does partially inhibit both the silver methods.

Comparison of the various staining methods (including the silver methods) and the various fixatives used, with particular note of the cytological quality of the sections, leads us to the conclusion that the new method is more consistently informative than the silver impregnations - the silver proteinate (Davenport and variants) and the Fontana-Masson. Probably the Fontana-positive cells (argentaffin) occurring in human tumours all also react with proteinate ; the other proteinate-positive cells, those that fail to react with Fontana, are described as argyrophils. Thus the less efficiently the Fontana method works, the greater the proportion of the tumour cells that have to be accepted as 


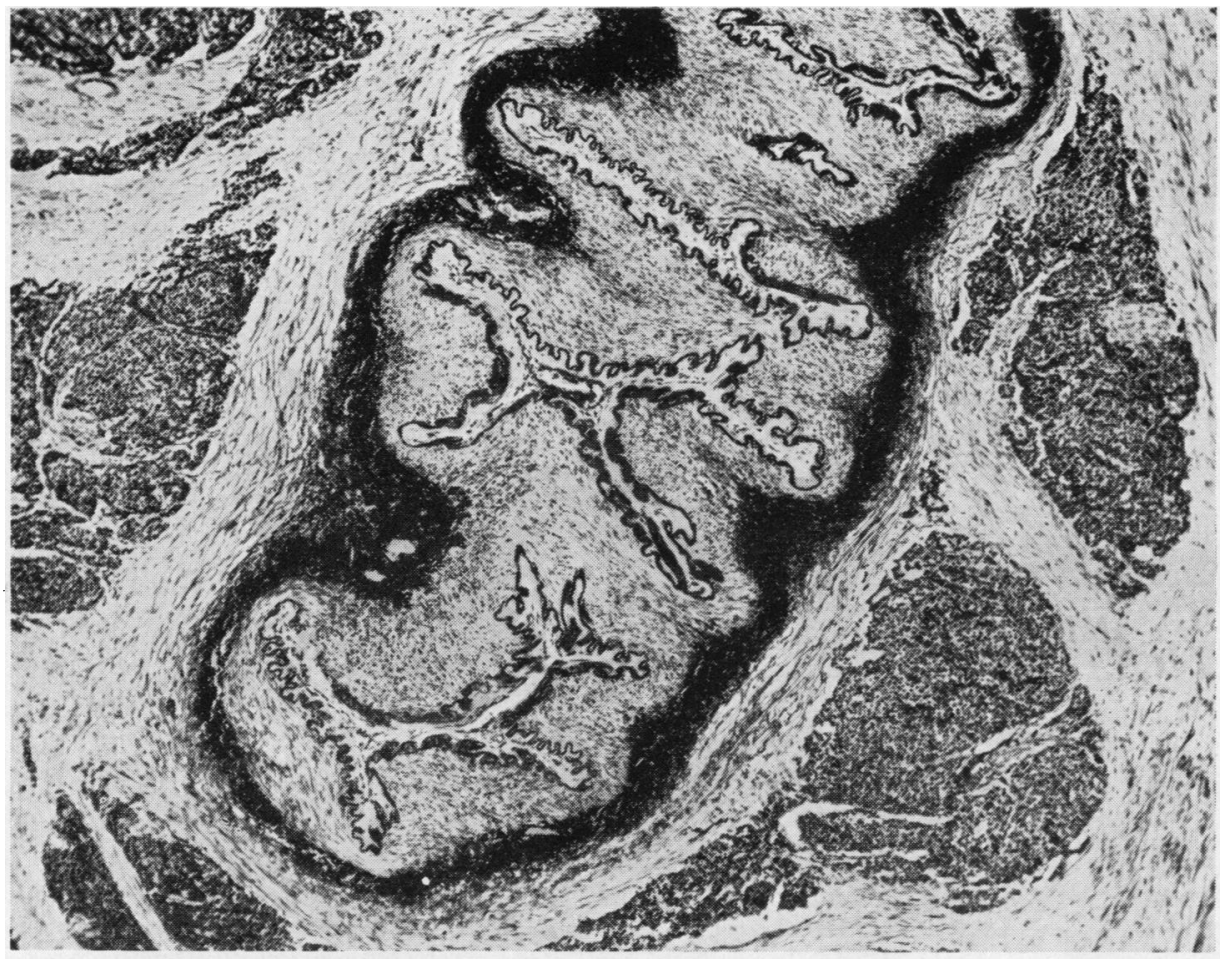

F1G. 6.-Artery, $\times$ 45. The elastica of this vessel from near an ileal carcinoid shows an intense phloxinophilia. Note the phloxincphilia of the adjacent tumour tissue. Stained: phloxin, "lissamine" flavine (Dundee 58-A). Minus-red filter. Newcastle case 57/5318.

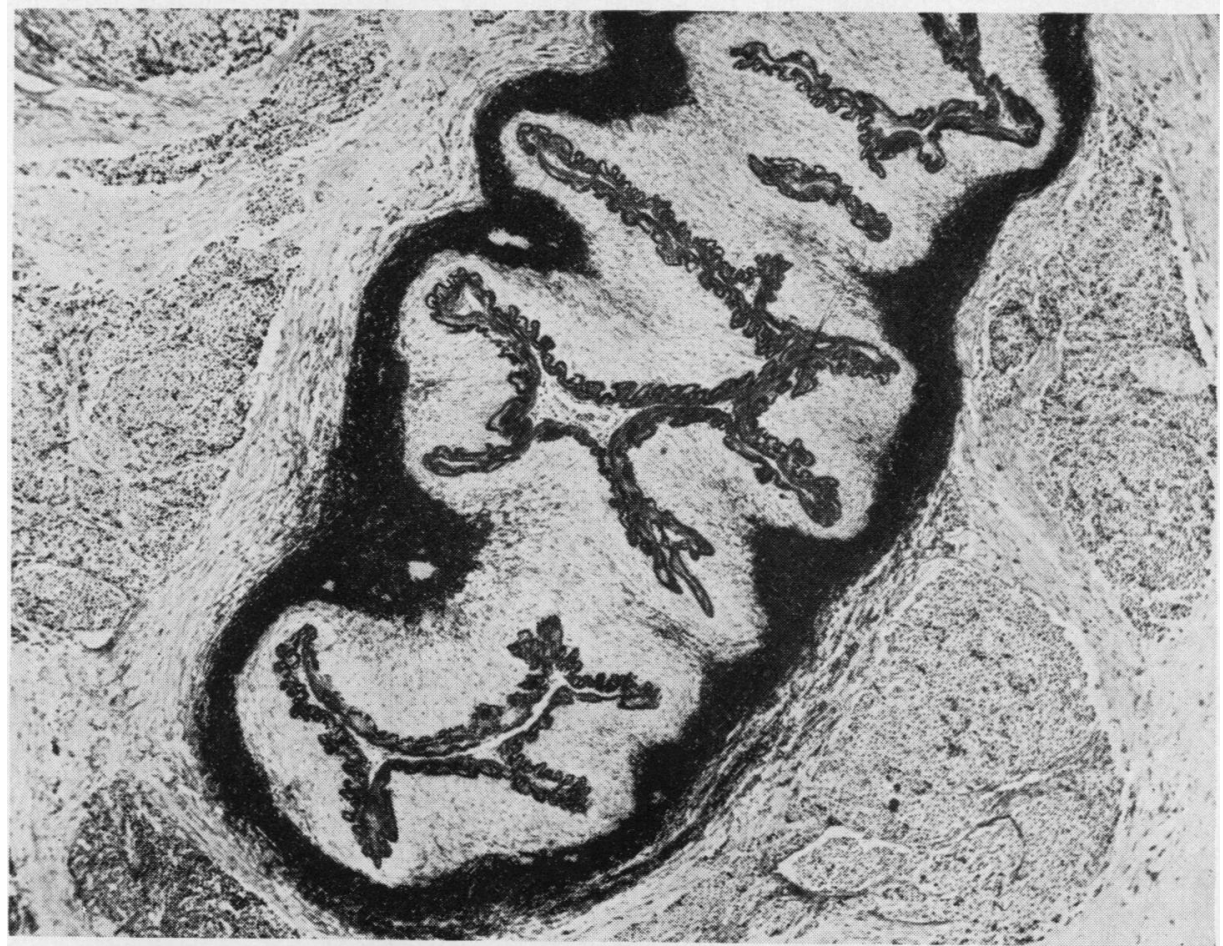

FIG. 7.-Artery, $\times$ 45. This is an adjacent section to show that the phloxinophil material in the last is in fact elastica. The Verhoeff stain gives a slight reaction with the granules of the tumour cells. Stained: Verhoeff and "lissamine" flavine. 
argyrophil cells. From our studies it seems clear that autolysis, poor formalin fixation, or the use of formol-corrosive (mercurial) fixation all reduce the granule content of the tumour cells as measured by the Fontana method. We, therefore, hesitate to accept any tumour as an argyrophilic tumour unless the authors accompany their assessment by proof of perfect fixation, and we would suggest that the chemical observations on 5-hydroxytryptophan excretion in the urine (Sandler and Snow, 1958) may be indicative of autolysis occurring within the inetastases. Our morphological observations do not justify us in thinking that there is more than one kind of carcinoid tumour.

In their study of the series of carcinoids, Lendrum and Fraser have found an extraordinary phloxinophilia in the elastic tissue which in the region adjacent to the tumour is increased in amount. In five cases there is not only an increase of stromal elastica but also a quite unusual amount and distribution of elastic tissue in large arteries (Figs. 6 and 7). This curious alteration raised the speculation that some product of the tumour has a directly stimulating effect on elastic tissue, and consequently attention was turned to the state of the elastic tissue in the pulmonary arterioles in the present case.

The Pulmonary Changes.-The possibility was envisaged that the circulating 5-HT might act on the elastica of the pulmonary vessels and thus be the first link in the chain of causation of the pulmonary hypertension. If in addition there were metastases in the lung it might be possible to observe more notable effects on the vessels adjacent to the metastases. From the microscopical study of the lung sections we thought that the interstitial elastica was in fact more obvious, indeed increased, around the larger pulmonary metastases. Moreover, some of the smaller pulmonary arteries adjacent to the metastases showed an apparent increase of elastica with splitting of the laminae and there were many large intimal proliferations which considerably reduced the vessel lumen.

Further, the variation in the changes in the arterioles measured, shown by the wide base of the hypertensive index graph, points to local effects even if it does not exclude a general effect. Unfortunately the reconstruction necessary to confirm these local effects was not possible on the 15 random blocks we had.

It is perhaps important to distinguish the two sets of observations on the carcinoid case. Firstly we have the generalized and focal elastosis in the stroma and vessels of the lung, a finding that is difficult to measure satisfactorily but one whose validity is strengthened by its similarity to the changes occurring near carcinoid tumour elsewhere, for example, around the primary in five of Lendrum and Fraser's cases of ileal carcinoid. Secondly we have the hypertensive index graph, based on absolute measurements, with its obvious abnormality and partial resemblance to the graphs obtained from the lungs from mitral stenosis and primary pulmonary hypertension.

It is commonly held that the structural abnormalities found in the pulmonary vasculature of these last two conditions are the result and not the cause of the hypertension; this view may be more emphatic than accurate even though its converse be untrue. Certainly our patient, six months before death, had a pulmonary artery pressure of only $22 / 10 \mathrm{~mm}$. $\mathrm{Hg}$, and to clinical observation she never provided evidence of pulmonary hypertension. Even at necropsy the only relevant feature was a slight fibrous thickening at the base of the pulmonic valve. Thus there was not enough pulmonary hypertension to provide us with obvious evidence of its existence, but there are changes in the lung that could reasonably be accepted as the result of pulmonary hypertension, and there is an elastosis that could be due to the products of carcinoid tumour. It is surely tempting to think that the elastosis is how the pulmonary haemodynamics are first upset in the carcinoid syndrome.

\section{Summary}

A case is described of functioning malignant carcinoid with clinical, haemodynamic, pharmacological, and necropsy data.

A new method is described for staining carcinoid tumour cells; a wide study of these tumours suggests that there is only one type of neoplastic cell.

Histological changes have been observed in the lung and its arterioles that may be a clue to the pulmonary hypertension of the carcinoid syndrome.

We are indebted to Dr. D. Emslie-Smith for his help at cardiac catheterization, Messrs. D. S. Fraser and W. Slidders for considerable technical assistance, Mrs. D. Kirkland for Figs. 2 to 5, and particularly Professor A. C. Lendrum for his encouragement and help with the manuscript. 
REFERENCES

Biörck, G., Axén, O., and Thorson, A. (1952). Amer. Heart J., 44,

Bridges, J. M., Gibson, J. B., Loughridge, L. W., and Montgomery, D. A. D. (1957) 'Brit. J. Surg. 45, 117 .

Code, C. F. (1937). J. Physiol. (Lond.), 89, 257.

Denst, J., Edwards, A., Neubuerger, K. T., and Blount, S. G. (1954). Amer. Heart J., 48, 506.

Goble, A. J., Hay, D. R., and Sandler, M. (1955). Lancet, 2, 1016. 544.

Goodale, F., and Thomas, W. A. (1954). A.M.A. Arch. Path., 58, 568

Hamperl, H. (1952). Virchows Arch. path. Anat., 321, 482.

and Lattes, R. (1957). Cancer, 10, 408.

Harrison, C. V. (1958). Brit. J. Radiol., 31, 217.

Heath, D., and Whitaker, W. (1956). Circulation, 14, 323.

Jacobson, W. (1957). Personal communication.

Jenkins, J. S., and Butcher, P. J. A. (1955). Lancet, 1, 331.

Kultschitzky, N. (1897). Arch. mikr. Anat., 49, 7 .

Laskey, A., and Greco, J. (1948). Arch. Path. (Chicago), 46, 83.

Lembeck, F. (1953). Nature (Lond.), 172, 910.

Lendrum, A. C. (1939). J. Path. Bact., 49, 590

- (1947). Ibid., 59, 399.

(1951). Recent Advances in Clinical Pathology, ed. S. C. Dyke, 2nd ed., pp. 516 and 519. Churchill, London.

Lubarsch, O. (1888). Virchows Arch. path. Anat., 111, 280.

MacDonald, R. A. (1956). Amer. J. Med., 21, 867.

and Robbins, S. L. (1957). A.M.A.Arch.Path., 63, 103

Macfarlane, P. S., Dalgliesh, C. E., Dutton, R. W., Lennox, B., Nyhus, L. M., and Smith, A. N. (1956). Scot. med. J., 1, 148.

Masson, P. (1914). C.R. Acad. Sci. (Paris), 158, 59

Mattingly, T. W. (1956). Med. Ann. D. C., 25, 239 and 304.

Mitchell, R. G., and Code, C. F. (1954). J. appl. Physiol., 6, 387

Mutt, H. R., and Code, C. F. (1954). J. clin. Invest., 33, 1199.

Oberndorfer, S. (1907). Frankfurt. Z. Path., 1, 426

O'Neal, R. M., Thomas, W. A., and Hartroft, P. M. (1955). A.M.A. Arch. Path., 60, 267.

Pearse, A. G. E. (1953). Histochemistry. Theoretical and Applied, p. 477. Churchill, London.

Pernow, B., and Waldenström, J. (1957). Amer. J. Med., 23, 16.

Ritchie, A. C. (1956). Amer. J. med. Sci., 232, 311.

Roberts, M., and Adam, H. M. (1950). Brit. J. Pharmacol., 5, 526.

Sandler, M., and Snow, P. J. D. (1958). Lancet, 1, 137.

Sjoerdsma, A., Weissbach, H., and Udenfriend, S. (1956). Amer. J. Med., $20,520$.

Terry, L. L., and Udenfriend, S. (1957). Ibid., 23, 5.
Smith, J. P and Campbell, A. C. P. (1956), J. Path. Bact., 72, 673.

Thorson, А. H. (1958). Acta med. scand., Suppl. 334.

- Biörck, G., Björkman, G., and Waldenstrom, J. (1954). Amer. Heart J., 47, 795 .

Valenzuela, C. T., Toriello, J., and Thomas, W. A. (1954). A.M.A. Arch. Path., 57, 51.

\section{A P P E N D I X}

The following red and yellow stain (Dundee 58-A) prepared by the method of A. C. Lendrum and D. S. Fraser was used on sections from the various metastases.

Stain with haemalum, etc., as usual.

Phloxin $0.5 \%$ in water plus $0.5 \%$ calcium chloride $-30 \mathrm{~min}$.

Rinse in cellosolve and then rinse in deodorized domestic kerosene (Aladdin Pink paraffin of Messrs. Shell-Mex).

Leave overnight in jar of kerosene.

Rinse in cellosolve and immerse in jar of saturated solution of "lissamine" flavine FFS (C.I 56205, Messrs. I.C.I.) in cellosolve.

Differentiation is adequate in three to four hours in well-fixed tissue, but sections of poor tissue may have to be taken out before the erythrocytes or even all the collagen have lost their red.

Rinse in cellosolve, in xylene, and mount.

Professor Lendrum acknowledges gratefully material from J. H. Biggart, A. C. P. Campbell, D. F. Cappell, A. Dick, J. S. Faulds, B. C. Morson, A. G. E. Pearse, J. H. Prain, G. H. Smith, and J. S. Young. 